\title{
Effects of experimentally planting non-crop flowers into cabbage fields on the abundance and diversity of predators
}

\author{
Nadine Ditner $\cdot$ Oliver Balmer • Jan Beck • Theo Blick • \\ Peter Nagel • Henryk Luka
}

Received: 17 January 2013/Accepted: 14 March 2013/Published online: 21 March 2013

(C) Springer Science+Business Media Dordrecht 2013

\begin{abstract}
Flowery field margins and intersowing of crops with flowers are used as management practices to promote arthropod biodiversity as well as biocontrol agents. Positive effects of enhancement (in abundance and species richness) of hymenopteran parasitoids on control of Lepidoptera pests have previously been demonstrated. However, effects on predatory arthropods, which may also serve as pest control agents, remain unclear. In an experimental study in cabbage fields we tested how sown flower strips on field margins and intersowing with cornflower affected the species richness, abundance and community composition of ground beetles and spiders. Furthermore, we investigated whether effects of flower margins are dependent on the distance from the field margins. We found that field margins generally harboured higher species richness, whereas effects on abundance were weaker. Intersown cornflower had positive effects on spider and ground beetle abundance, but affected species richness only weakly. Our results do not provide evidence for effects of distance from the flowery field margins on predator richness or
\end{abstract}

Electronic supplementary material The online version of this article (doi:10.1007/s10531-013-0469-5) contains supplementary material, which is available to authorized users.

\footnotetext{
N. Ditner · O. Balmer · H. Luka

Department of Plant Protection and Biodiversity, Research Institute of Organic Agriculture (FiBL), Ackerstrasse 21, 5070 Frick, Switzerland
}

N. Ditner · J. Beck $(\bowtie) \cdot$ P. Nagel $\cdot$ H. Luka

Department of Environmental Sciences (Biogeography), University of Basel, St Johanns-Vorstadt 10, 4056 Basel, Switzerland

e-mail: jan.beck@unibas.ch

O. Balmer

Swiss Tropical and Public Health Institute, Socinstrasse 57, 4051 Basel, Switzerland

T. Blick

Callistus-Gemeinschaft für Zoologische \& Ökologische Untersuchungen, Heidloh 8, 95503 Hummeltal, Germany

T. Blick

Senckenberg, Forschungsinstitut und Naturmuseum, Hessische Naturwaldreservate,

Senckenberganlage 25, 60325 Frankfurt am Main, Germany 
abundance. Species composition was strongly affected by the habitat management actions. We conclude that habitat management practices like flower strips on field margins and intersowing with flowers, which are primarily added to attract and enhance parasitoids for pest control, also benefit biodiversity conservation in spiders and ground beetles. They also positively affect the abundance of these primarily predatory taxa, which adds to the biocontrol potential of non-crop flowering plants.

Keywords Araneae $\cdot$ Carabidae $\cdot$ Companion plants $\cdot$ Flower strips $\cdot$ Habitat management $\cdot$ Organic farming $\cdot$ Pest control

\section{Introduction}

Habitat loss and the intensification of agriculture have led to a dramatic decline of biodiversity in Europe since the early twentieth century (Weibull et al. 2000; Stoate et al. 2001; Robinson and Sutherland 2002; Holland and Reynolds 2003; Haaland et al. 2011). This has been shown particularly clearly for ground beetles (Marggi 1992; Duelli 1994; Holland 2002; Huber and Marggi 2005; Kotze and O'Hara 2003; Luka et al. 2009). Biodiversity loss may impede ecosystem services (such as providing food, water, genetic resources, erosion control, pest regulation, soil formation, efficient nutrient cycling, pollination) and diminish the cultural value of a landscape (e.g. for recreation, aesthetics and spirituality; Gurr et al. 2003; MEA 2005; Tscharntke et al. 2005). However, biodiversity in agro-ecosystems can be managed, i.e. enhanced, by appropriate measures (Kromp and Steinberger 1992; Altieri 1999). Complex habitats benefit both biological control agents and biodiversity in general (Altieri and Letourneau 1982; Bianchi et al. 2006; Pisani Gareau and Shennan 2010). Therefore, subsidies for ecological compensation areas have been introduced across Europe to counter biodiversity loss (for Switzerland: Jordi 2010). Non-production areas set aside for compensation provide shelter, alternative food sources, undisturbed overwintering sites or larval development sites to a wide range of species and lead to a diversification of microclimate and vegetation structure (Dennis and Fry 1992; Landis et al. 2000; Pfiffner and Luka 2000; Geiger et al. 2009). Such measures have been demonstrated to increase pollinator species richness in adjacent fields (Franzen and Nilsson 2008), and they greatly increase the numbers of overwintering arthropod species with beneficial effects on agriculture (Pfiffner and Luka 2000; Hatteland et al. 2011). Compensation areas are often designed as strips in or along fields, consisting of a variety of semi-managed plant communities, among them flower mixtures (e.g., Pfiffner et al. 2009). Strips are often established along fields of cereals and root crops to increase populations of biological control agents (e.g. predatory insects, parasitoids), but little is known about the effects of compensation measures in vegetable crops. To enhance beneficial insects in cabbage cultures, intercropping with clover (e.g., Armstrong and McKinlay 1997; Finch and Kienegger 1997; Schellhorn and Sork 1997) or grass strips has been applied (e.g., Ryan et al. 1980). Weedy cabbage fields were shown to contain less insect pests than weedfree cultures (Schellhorn and Sork 1997).

The aim of this study was to investigate options for biodiversity management of grounddwelling, predatory arthropods (i.e., spiders and ground beetles) by experimental introduction of non-crop flowering plants in two spatial schemes. This involved establishing flower strips along field margins. However, because potential effects of flower strips could be restricted to the direct vicinity of the strips (Luka et al. 2001; Tylianakis et al. 2004; Lavandero et al. 2005), we also investigated effects of companion plants inside the field. 
We expected that these would attract target insects from the strips into the field and thus spread the effects of the strips.

Specifically we asked: (1) Do flower strips affect community properties of ground beetles and spiders? (2) Is the distance from flower strips on field margins related to community properties of ground beetles and spiders in fields? (3) Do the companion plants inside the fields affect community properties of ground beetles and spiders in fields?

Abundance of predators (i.e., individual numbers, regardless of species identity) is evidently related to biocontrol, whereas species richness is a variable relevant to both general conservation efforts (i.e., increasing alpha-diversity in the landscape) as well as biological pest control. Different predator species may differ in feeding niches, so they (potentially) prey on different pest organisms. We investigated experimental effects on both response variables. Ground beetles and spiders are well suited to address these questions because (1) they are species-rich and they occur in large numbers in agricultural as well as natural habitats (Hänggi 1989; Luka 1996; Blick et al. 2004). In Switzerland alone, 523 Carabidae (Luka et al. 2009) and 970 Araneae species (Blick et al. 2004; Hänggi and Stäubli 2012) are known. (2) Most ground beetles are polyphagous and all spiders are zoophagous, hence they act as natural control agents (Dempster 1967; Luff 1987; Luka 1996; Suenaga and Hamamura 1998; Gurr 2000; Holland 2002). Furthermore (3) the taxonomy of the European species is well studied (Müller-Motzfeld 2006; Luka et al. 2009) and their habitat requirements are well known and (4) they react sensitively and fast to environmental changes and are easily surveyed with reproducible methods (Nagel 1999; Rainio and Niemela 2003; Luka 2004). As a consequence, they are often utilized as bioindicators in conservation studies (but see Beck et al. 2013).

\section{Materials and methods}

\section{Location and experimental design}

We collected arthropods in seven organic white cabbage (Brassica oleracea) fields (mean area $8,800 \mathrm{~m}^{2}$ ) in the northern Swiss lowlands (see Table 1 for site details). A $3 \mathrm{~m}$-wide flower strip (FS) was planted along one long margin of each field. Within each field we installed an area with companion plants $(\mathrm{CP}+)(12 \times 26 \mathrm{~m}$; cornflower (Centaurea cyanus) planted between cabbage at a density of $1 \mathrm{~m}^{-2}$ ). At $40 \mathrm{~m}$ distance an equally large area without companion plants $(\mathrm{CP}-)$ served as control. Cabbage fields had sizes of at least $50 \times 100 \mathrm{~m}$, hence edge effects on survey areas should be negligible. $\mathrm{CP}+$ and $\mathrm{CP}$ - each contained a survey area "close" $(5 \mathrm{~m})$ and "far" $(20 \mathrm{~m})$ from the flower strip. The flower strip contained two survey areas adjacent to $\mathrm{CP}+$ and $\mathrm{CP}-$. Per survey area one pair of funnel traps, five meters apart, was set up (Fig. 1) from June 29th to September 9th.

The flower strips were sown in April 2010 with a seed mixture composed of $15 \mathrm{~g}$ Vicia sativa, $9 \mathrm{~g}$ Fagopyrum esculentum, $4 \mathrm{~g}$ Ammi majus and $2 \mathrm{~g}$ Centaurea cyanus and $70 \mathrm{~g}$ vermiculite (to facilitate sowing) per $100 \mathrm{~g}$ of mixture (provided by Fenaco Genossenschaft, Sämereizentrum Niderfeld, Winterthur, Switzerland). This forb mixture ensured high ground coverage and inhibited the establishment of weeds. The cabbage plants were planted between May 19th and June 29th, 2010; companion plants were planted shortly thereafter (Table 1). 


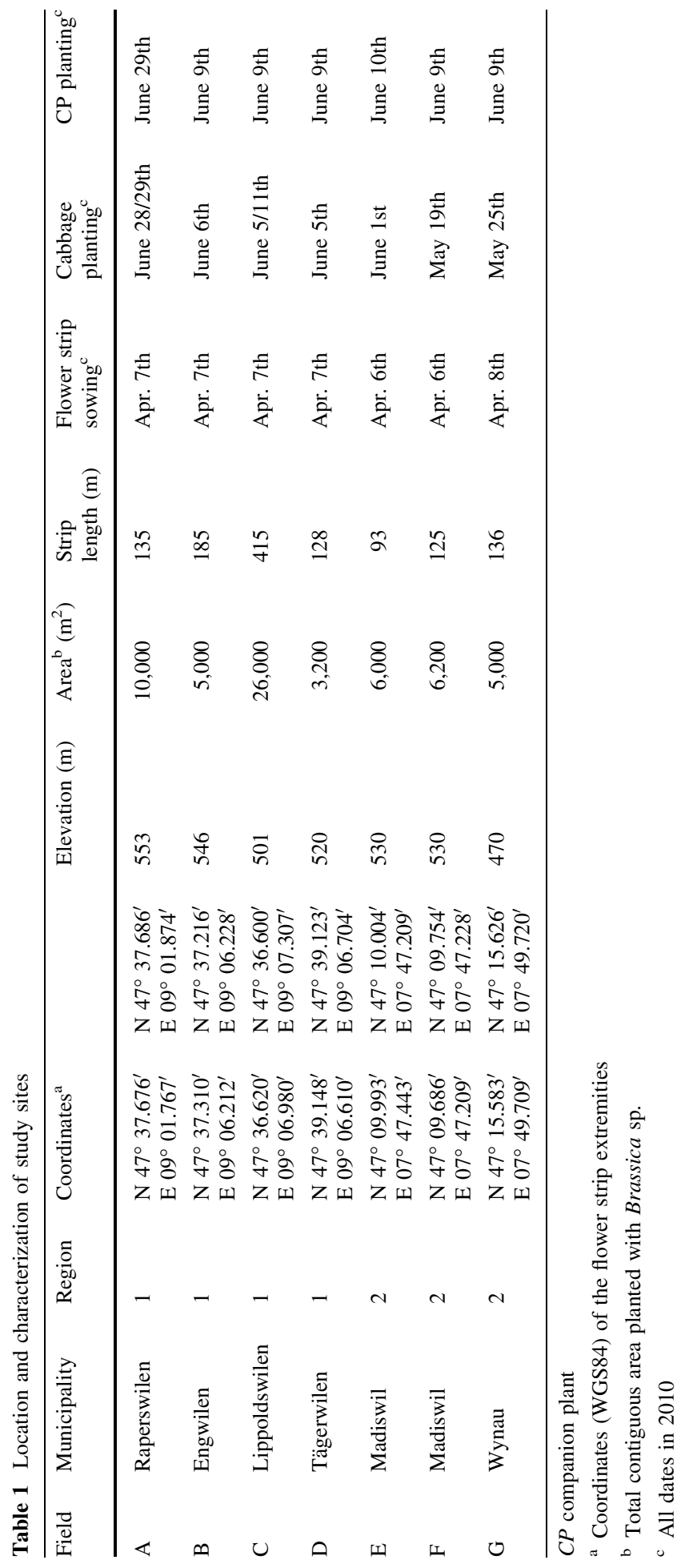


Fig. 1 Experimental design: Cabbage field (white area) bordered by a flower strip (FS) (grey shaded area). Cabbage fields contained an area with cornflowers (Centaurea cyanus) as companion plants $(\mathrm{CP}+$, dotted) and a control area without companion plants $(\mathrm{CP}-$, white $)$. Six survey areas (dashed ellipses) containing two funnel traps each (filled circles) were set up. Seven fields in two regions were sampled (Table 1)

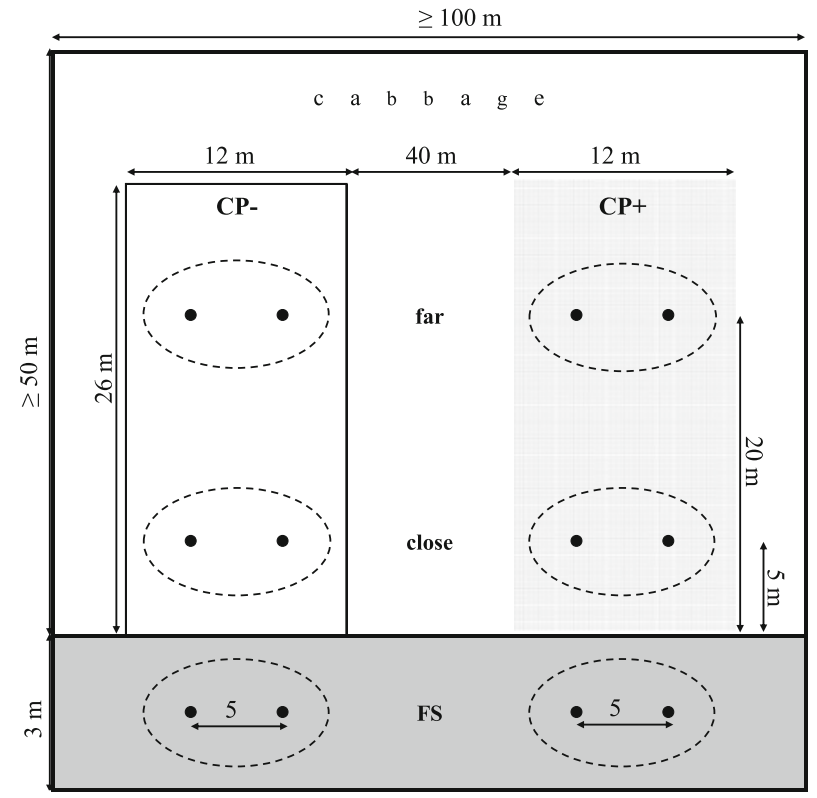

\section{Measurements}

Epigean arthropods were caught in funnel traps between June 29th and September 7th, 2010 (a period of 85 days). Traps were emptied fortnightly. Funnel traps consisted of a pipe of $10 \mathrm{~cm}$ diameter buried level to the soil surface, in which a funnel of $10 \mathrm{~cm}$ diameter was placed that ended in a $300 \mathrm{ml}$ container filled to one-third with ethylene glycol $(100 \%)$ and a drop of soap (Gall-Seife flüssig, Permatin AG, Stein am Rhein, Switzerland) to reduce surface tension. To avoid flooding by rain water, traps were covered with a transparent plastic roof $5 \mathrm{~cm}$ above the ground.

All Carabidae and Araneae were identified to species level. The nomenclature of ground beetles followed Luka et al. (2009) corresponding to Löbl and Smetana (2003), that of spiders followed Platnick (2012). We measured activity density (i.e., number of individuals in traps) as a proxy of abundance, and species richness as a measure of diversity. Species richness may be affected by incomplete local sampling, but evaluation of species accumulation curves indicated that we assessed the local fauna at the sampling period quite completely (not shown).

In each sampling area a botanic inventory (ground coverage per plant species) was carried out according to Braun-Blanquet (1964) between July 29th and August 6th, 2010 to record both planted and spontaneous vegetation (i.e., weeds). Within the cabbage fields we surveyed an area of $4 \times 12 \mathrm{~m}$, whereas survey areas within the flower strip were $3 \times 12 \mathrm{~m}$ in size.

\section{Analysis}

All temporal replicates per trap were pooled per trap (see Fig. 1). Furthermore, for the analysis of habitat treatments $(\mathrm{FS}, \mathrm{CP}+, \mathrm{CP}-)$, the four traps within the same treatment 
per field were pooled (Fig. 1). For comparisons of effects of companion plants and distance from flower strips, the two traps of each survey area (Fig. 1) were pooled.

We tested for effects of experimental habitat treatments (FS, $\mathrm{CP}+, \mathrm{CP}-$ ) with linear mixed effects models in $\mathrm{R}$ ( $\mathrm{R}$ Development Core Team 2009; function lme of package nlme), using site as random factor. Species richness values and activity densities of spiders were normally distributed and data are reported as arithmetic mean plus or minus the standard error $(\bar{x} \pm \mathrm{se})$. Activity densities of ground beetles were log-transformed to follow assumptions of parametric models. Therefore, means are reported as geometric mean times or divided by the multiplicative standard deviation $\left(\bar{x}^{* *} / \mathrm{s}^{*}\right.$; Limpert et al. 2001).

In a second step, we tested for effects of companion plant presence, distance from the flower strip, and their interaction, using only data from within the fields (i.e., not from flower strips) $\left(\mathrm{CP}+_{\text {close }}, \mathrm{CP}+_{\text {far }}, \mathrm{CP}-_{\text {close }}, \mathrm{CP}+_{\text {far }}\right)$ with linear mixed effects models, using site as random factor. Activity densities and species richness were normally distributed and reported as arithmetic mean plus or minus the standard error $(\bar{x} \pm \mathrm{se})$. Additionally, we applied a nested linear mixed effects model to investigate the effect of companion plant presence at the two distances from the flower strip, using only data from within the fields.

The influence of environmental and management variables on the faunal composition of ground beetles and spiders was studied using canonical correspondence analysis (CCA; software CANOCO for Windows 4.5, ter Braak and Smilauer 1998). Region, plant cover, plant species diversity and experimental habitat treatment were used as environmental predictors. We applied forward selection-CCA. The significance of effects were assessed by 499 Monte Carlo permutations, testing the eigenvalue of the axis associated with this variable (ter Braak 1996).

Carabidae species were classified as rare according to the Swiss Red List (Duelli 1994), whereas for rare Araneae we followed the most recent German Red List (Blick et al. 2013) as no Red List is available for Switzerland yet. Species were qualified as frequent if they occurred with at least nine individuals. We defined species to preferentially occur in one region or habitat type if at least $2 / 3$ of individuals were found in that region or habitat type.

\section{Results}

Abundance and species richness

A total of 27,682 ground beetles belonging to 70 species and 9,942 spiders belonging to 65 species were caught. The most frequent ground beetles were Harpalus rufipes $(28 \%$ of carabid individuals), Bembidion quadrimaculatum (16\%) and Poecilus cupreus (13\%). The most frequent spiders were Oedothorax apicatus (62\% of spider individuals), Erigone dentipalpis (8.6 \%) and Pardosa agrestis (6.6\%; Electronic Supplement). Per site medians were 3,538 specimens and 40 species of ground beetles, and 1,301 specimens and 29 species of spiders (Table 2).

Experimental habitat treatment $(\mathrm{FS}, \mathrm{CP}+, \mathrm{CP}-)$ generated significant differences in species richness of both taxa (Table 3). Flower strips sheltered 20 ground beetle species more (approx. $30 \%$ ) than the two habitat types within fields. Spider species richness was highest in flower strips and lowest in the treatment without companion plants. Ground beetle abundance was not significantly influenced by treatment type, and the effect was marginal for spiders. The significant effects were caused mainly by differences between flower strips and fields. Only spider species richness showed significantly higher values in the treatment with companion plants than in the treatment without companion plants. 
Table 2 Total species richness (S) and activity density (AD) of treatments (FS, flower strip; $\mathrm{CP} \pm$, with/ without companion plants, close and far from the flower strip)

\begin{tabular}{lrrrrr}
\hline & \multicolumn{1}{c}{$\mathrm{FS}$} & $\mathrm{CP}+_{\text {close }}$ & $\mathrm{CP}+_{\text {far }}$ & $\mathrm{CP}-_{\text {close }}$ & $\mathrm{CP}-_{\text {far }}$ \\
\hline $\mathrm{S}$ (carab) & 66 & 38 & 38 & 36 & 36 \\
$\mathrm{AD}$ (carab) & 13,961 & 3,500 & 3,895 & 3,365 & 2,961 \\
$\mathrm{~S}$ (spid) & 54 & 32 & 31 & 28 & 25 \\
AD (spid) & 2,386 & 2,002 & 2,117 & 1,580 & 1,857 \\
\hline
\end{tabular}

Across seven fields (see Table 1) an average $( \pm$ SE) of 3,954.6 $( \pm 1258.9)$ ground beetle individuals of 39.4 $( \pm 2.0)$ species and 1,335.2 $( \pm 628.2)$ spider individuals of $28.3( \pm 4.1)$ species were caught

Table 3 Mean \pm SE of species richness (S) and activity density (AD) per taxon and habitat treatment (gmean*/gse for carbid activity densities; see "Materials and methods") and test statistics of linear mixed effect models

\begin{tabular}{llllrr}
\hline & FS & CP & CP - & $F_{d f=12}$ & $p$ \\
\hline S (carab) & $35.0^{\mathrm{a}} \pm 1.3$ & $22.9^{\mathrm{b}} \pm 0.3$ & $22.7^{\mathrm{b}} \pm 1.0$ & 84.0 & $<0.001$ \\
AD (carab) & $1,580.1^{\mathrm{a} * / 1.3}$ & $999.1^{\mathrm{a} * / 1.1}$ & $859.8^{\mathrm{a} * / 1.1}$ & 2.5 & 0.123 \\
S (spid) & $23.0^{\mathrm{a}} \pm 1.1$ & $17.3^{\mathrm{b}} \pm 1.1$ & $14.3^{\mathrm{c}} \pm 0.4$ & 23.9 & $<0.001$ \\
AD (spid) & $340.9 \pm 47.0$ & $588.4 \pm 116.6$ & $491.0 \pm 100.4$ & 4.0 & 0.047 \\
\hline
\end{tabular}

Different letters behind values indicate significant pairwise differences between treatments

Within the cabbage fields, companion plant presence positively affected spider species richness and abundance as well as ground beetle abundance (Table 4). However, there were no significant effects of distance from flower strips (Table 4). Companion plants did increase ground beetle activity densities far from the flower strip $\left(\mathrm{F}_{18}=9.462\right.$, $p=0.006)$, but not close to the flower strip $\left(\mathrm{F}_{18}=0.198, p=0.662\right)$, whereas this effect was reversed for spider activity densities (near: $\mathrm{F}_{18}=6.705, p=0.018$; far: $\mathrm{F}_{18}=2.545$, $p=0.128$ ) and species richness (near: $\mathrm{F}_{18}=6.927, p=0.017$; far: $\mathrm{F}_{18}=4.051$, $p=0.059)$.

Table 4 Mean \pm SE of species richness (S) and activity density (AD) per taxon and habitat treatment, using only data from within fields

\begin{tabular}{|c|c|c|c|c|c|c|c|c|}
\hline & $\mathrm{CP}+{ }_{\text {close }}$ & $\mathrm{CP}+{ }_{\text {far }}$ & $\mathrm{CP}-{ }_{\text {close }}$ & $\mathrm{CP}-_{\text {far }}$ & $\begin{array}{l}\text { Pres: } \\
\text { F }_{d f=19}\end{array}$ & $p$ & $\begin{array}{l}\text { Dist: } \\
F_{d f=19}\end{array}$ & $p$ \\
\hline $\mathrm{S}_{\text {(carab) }}$ & $18.9 \pm 1.0$ & $18.4 \pm 1.3$ & $18.6 \pm 1.0$ & $17.9 \pm 1.1$ & 0.231 & 0.636 & 0.410 & 0.530 \\
\hline $\begin{array}{l}\mathrm{AD} \\
\text { (carab) }\end{array}$ & $500.0 \pm 54.6$ & $556.4 \pm 83.3$ & $480.7 \pm 66.2$ & $423.0 \pm 46.8$ & 5.486 & 0.003 & 0.000 & 0.984 \\
\hline S (spid) & $14.0 \pm 1.3$ & $12.9 \pm 0.74$ & $11.6 \pm 0.5$ & $11.0 \pm 0.7$ & 11.265 & 0.003 & 1.802 & 0.195 \\
\hline $\begin{array}{l}\mathrm{AD} \\
\text { (spid) }\end{array}$ & $286.0 \pm 63.0$ & $302.4 \pm 58.0$ & $225.7 \pm 49.7$ & $265.3 \pm 52.3$ & 8.996 & 0.007 & 2.972 & 0.101 \\
\hline
\end{tabular}

Test statistics from linear mixed effect models for effects of companion plant presence (Pres) and distance from flower strip (Dist) are given. Notably, effects of companion plants on the AD of Carabidae were stronger far from flower strips than near them, whereas the opposite was observed for effects on $\mathrm{S}$ and $\mathrm{AD}$ of spiders (details not shown) 
Effects on community composition

Region, plant ground cover and habitat treatment significantly affected species community composition (CCA: $p<0.008$ ). Ground beetle and spider species community compositions differed, in particular, between flower strip and the two treatment types within fields. Plant ground cover explained most variability of species community composition, i.e. 18.3 and $16.4 \%$ for ground beetles and spiders, respectively, followed by treatment type and region explaining ca. $15 \%$ of compositional variance each, for both taxa. Plant species richness played a significant role only for ground beetles (explaining $13.6 \%$ of variation). Additional analyses (not shown) could not establish significant effects of distance from field margins on community compositions.

The ordination of ground beetle data indicated that species communities of the two regions are distinct (Fig. 2). Communities of region 1 (fields A, B, C and D) are located on the bottom right of the ordination plot, whereas communities of region 2 (fields $\mathrm{E}, \mathrm{F}$ and $\mathrm{G}$ ) are on the top left. The same pattern, though less pronounced, is observed in the ordination of spider data (Fig. 2). Variation in ground beetle community composition between regions was related to known species-specific habitat preferences for xerophilous and pioneer flora habitats (region 1) as opposed to eurytopic species typical of arable land (region 2).

Eighteen of 70 recorded ground beetle species and 22 of 65 spider species occurred only in flower strips, nine species of each group with more than one individual. In contrast, only one ground beetle species (Tachys bistriatus) occurred exclusively within fields (60 individuals). Araneae species exclusive to cabbage fields were singletons (hence habitat preference is hard to judge), but seven frequent spiders species were more frequent in cabbage fields than in flower strips. Five rare, red-listed ground beetle species were found (49 specimens in total: Amara kulti, A. littorea, Dolichus halensis, Porotachys bisulcatus, Trechoblemus micros). Four of these occurred mainly in the flower strips. No spider species from the German Red List were found, but 3 recorded species (7 specimens in
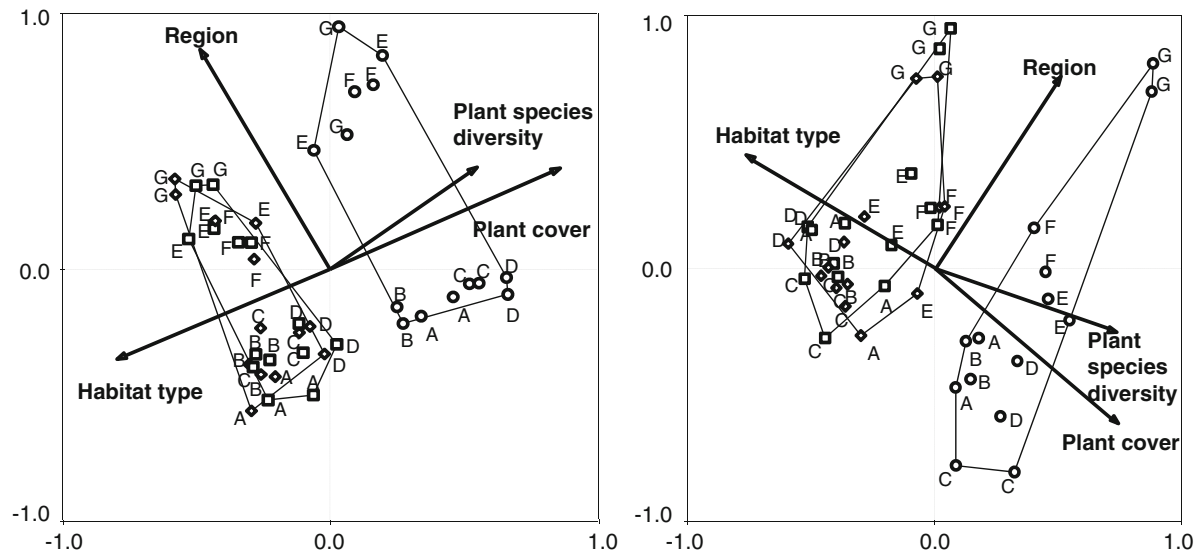

Fig. 2 Canonical correspondence analysis (CCA) plots of carabid (left) and spider (right) species community composition resemblance between habitat treatments (FS circles; $\mathrm{CP}+$ square; $\mathrm{CP}-$ diamonds). Letters indicate fields (Table 1). Arrow orientation and length indicate direction and strength of correlations with the respective environmental predictors. Convex polygons enclose all sites of each habitat treatment. See Electronic Supplement for details on explained variance and significance of variables 
total: Drassyllus praeficus, Xerolycosa miniata, Robertus arundineti) are red-listed for the southern German state of Baden-Württemberg (Nährig et al. 2003).

\section{Discussion}

Potential of habitat management for conservation and pest control

Flower strips and companion plants are promoted for a double purpose in agriculture - on the one hand, they are expected to serve biodiversity conservation (Smith et al. 2008; Merckx et al. 2013), on the other hand they may promote the presence and abundance of biological pest control agents, such as predatory and parasitoid arthropods. Here we treated only ground-dwelling, predatory taxa, but similar studies on parasitoid Hymenoptera (e.g., Pfiffner et al. 2009; Géneau et al. 2012; Belz et al. 2013) showed evidence for the presence of both effects.

Our data clearly indicated that flower strips can enhance local species richness, hence contributing to the biodiversity of agricultural landscapes. Species richness of both ground beetles and spiders were higher in flower strips than in fields, they harboured a different species community than that found in fields (adding to the regional species richness), and they contained more species of national conservation relevance (i.e., red-listed taxa). This indicates the conservation potential of such management actions.

Data were more equivocal with regard to the effects of flowers on the pest control potential of these predatory taxa. Because ground beetles and spiders are less preyspecific than, e.g., parasitoids, we would expect pest-control benefits particularly from increased abundance, and less from increased species richness (despite potential effects of a larger prey spectrum, see "Introduction"). However, effects of flower strips on abundance (i.e., activity densities) were weak, whereas companion plants lead to significantly increased abundance when analysed separately from flower strip effects. This was particularly the case for ground beetles far from flower strips (despite the absence of other distance effects). Cultivating vegetable crops such as cabbage requires high intensity techniques (e.g., mechanical weed removal, fertilizer) compared to cereal crops, which may be related to the fact that stronger field margin effects onto ground beetles and spider communities had been found in earlier studies in cereal fields (Luka et al. 2001).

There is some support for companion plants increasing the density of predatory arthropods in fields far from pest control-managed field edges. This suggests that follow-up studies on the effects of these predators, i.e. on pest density and/or agricultural productivity, would be useful to allow an economic judgment on the use of companion plants for pest control (see above for established effects on parasitoids). Possibly effects of companion plants were weaker than those of flower strips simply because less species were used for the former than for the latter (i.e., one vs. four), which also affects structural complexity of the vegetation. However, economic constraints (i.e., the need to harvest cabbage) limit the choices for additional plants.

Ground beetles were found to be powerful biocontrol agents of cabbage pests in earlier studies (e.g., Schellhorn and Sork 1997; Shelton et al. 1983; Suenaga and Hamamura 1998, 2001). Dempster (1967), for example, estimated that over half of the mortality of the first two caterpillar instars of Pieris rapae (Lepidoptera) was due to predation by arthropods, especially the carabid Harpalus rufipes, and to lesser degrees Abax parallelepipedus and Trechus quadristriatus. On our study sites the pest species $P$. rapae occurred abundantly, 
while predatory $H$. rufipes and Bembidion quadrimaculatum were the most frequently encountered ground beetles. Harpalus rufipes were most abundant in flower strips, whereas B. quadrimaculatum seemed to profit from companion plants.

Armstrong and McKinlay (1997) observed that cabbage cultures with natural weed cover had more ground beetles than dense cabbage cultures with dense white clover undergrowth. In contrast, Purvis and Curry (1984) observed no correlation between partial weed cover and trap contents. Schellhorn and Sork (1997) and Dempster (1969) demonstrated that crucifer cultures with weed cover contained fewer pests and higher predator abundance, particularly ground beetles. These studies and our results underline the potential of management measures on pest control by predators (e.g. Pfiffner et al. 2009; Géneau et al. 2012) as a surplus to documented effects by parasitoids.

Why do flowering plants affect predatory beetles and spiders?

Unlike parasitoid Hymenoptera, many of which are nectar-feeding as adults, only few ground beetles and none of the spiders utilize flowers as a food resource. This raises the question why the presence of flowers would affect their abundance and community structure. The habitat preferences of ground beetles are, at local scale, mainly linked to microclimate, i.e. moisture, temperature and light conditions (Thiele 1977). Furthermore, interspecific competition and vegetation density, which impair the mobility of some species, were identified as determinants of local species compositions (Dornieden 2005). Flower strips and companion plants most probably affect ground beetles and spiders by their impact on vegetation structure and consequent microclimatic changes. Furthermore, flower strips may promote the abundance and diversity of their (herbivorous) prey (Meek et al. 2002, Haaland et al. 2011; Bohan et al. 2011).

\section{Conclusions}

Apart from previously established benefits of flower strips and companion plants on parasitoids in vegetable fields, we found that such measures (particularly flower strips) clearly benefit conservation efforts in ground beetles and spiders (i.e., promoting species richness and the occurrence of rare species). Effects of habitat management measures on abundance of these predatory taxa were more equivocal, and follow-up studies will be required to evaluate how agronomically and economically relevant the pest control effects of these taxa are.

Acknowledgments We thank all farmers and Rathgeb's Bioprodukte (Unterstammheim, Switzerland) for making their fields available, Lukas Pfiffner (Research Institute of Organic Agriculture (FiBL) for discussions on experimental design, Nadja Haefeli, Bettina Weishaupt and Sebastian Moos for help with field and lab work, and Andreas Schötzau for statistical support. Werner Marggi (Natural History Museum Bern) helped with taxonomic identification of some Carabidae and Heiner Lenzin (University of Basel) with botany. The project was financially supported by the Bristol Foundation, the Federal Office for the Environment (BAFU), the Parrotia-Foundation, the Werner Steiger Foundation, the Ernst Göhner Foundation, the Singenberg Foundation, the Spendenstiftung Bank Vontobel, Schöni Swissfresh AG and the Stiftung zur internationalen Erhaltung der Pflanzenvielfalt. 


\section{References}

Altieri MA (1999) The ecological role of biodiversity in agroecosystems. Agric Ecosyst Environ 74:19-31 Altieri MA, Letourneau DK (1982) Vegetation management and biological control in agroecosystems. Crop Prot 1:405-430

Armstrong G, McKinlay RG (1997) Vegetation management in organic cabbages and pitfall catches of carabid beetles. Agric Ecosyst Environ 63:267-276

Beck J, Pfiffner L, Ballesteros-Mejia L, Blick T, Luka H (2013) Revisiting the indicator problem: can three epigean arthropod taxa inform about each other's biodiversity? Divers Distrib, online early. doi: $10.1111 /$ ddi. 12021

Belz E, Kolliker M, Balmer O (2013) Olfactory attractiveness of flowering plants to the parasitoid $M i$ croplitis mediator: potential implications for biological control. Biocontrol. doi:10.1007/s10526012-9472-0

Bianchi FJ, Booij CJ, Tscharntke T (2006) Sustainable pest regulation in agricultural landscapes: a review on landscape composition, biodiversity and natural pest control. Proc Roy Soc B 273:1715-1727

Blick T, Pfiffner L, Luka H (2000) Epigäische Spinnen auf Äckern der Nordwest-Schweiz im mitteleuropäischen Vergleich (Arachnida: Araneae). Mitteilungen der Deutschen Gesellschaft für allgemeine und angewandte Entomologie 12:267-276

Blick T, Bosmans R, Buchar J, Gajdos P, Hänggi A, Van Helsdingen P, Ruzicka V, Starega W, Thaler K (2004) Checklist of the spiders of Central Europe (Arachnida: Araneae), version 1. http:// www.arages.de/. Accessed Nov 2012

Blick T, Finch O-D, Harms KH, Kiechle J, Kielhorn K-H, Kreuels M, Malten A, Martin D, Muster C, Nährig D, Platen R, Rödel I, Scheidler M, Staudt A, Stumpf H, Tolke D (2013) Rote Liste der Spinnen Deutschlands (Araneae). Naturschutz und Biologische Vielfalt 70(4)

Bohan DA, Boursault A, Brooks DR, Petit S (2011) National-scale regulation of the weed seedbank by carabid predators. J Appl Ecol 48:888-898

Braun-Blanquet J (1964) Pflanzensoziologie: grundzüge der vegetationskunde. Springer, Wien

Dempster JP (1967) The control of Pieris rapae with DDT. I. The natural mortality of the young stages of Pieris. J Appl Ecol 4:485-500

Dempster JP (1969) Some effects of weed control on the numbers of the small cabbage white (Pieris rapae L.) on brussels sprouts. J Appl Ecol 6:339-345

Dennis P, Fry GLA (1992) Field margins: can they enhance natural enemy population densities and general arthropod diversity on farmland? Agric Ecosyst Environ 40:95-115

Dornieden K (2005) Laufkäfer, Carabidae. Ökoporträt (NVH/BSH) 38:1-5

Duelli P (1994) Rote Listen der gefährdeten Tierarten der Schweiz. Bundesamt für Umwelt, Bern

Finch S, Kienegger M (1997) A behavioural study to help clarify how undersowing with clover affects hostplant selection by pest insects of brassica crops. Entomol Exp Appl 84:165-172

Franzen M, Nilsson SG (2008) How can we preserve and restore species richness of pollinating insects on agricultural land? Ecography 31:698-708

Geiger F, Wackers F, Bianchi F (2009) Hibernation of predatory arthropods in semi-natural habitats. Biocontrol 54:529-535

Géneau CE, Wäckers FL, Luka H, Daniel C, Balmer O (2012) Selective flowers to enhance biological control of cabbage pests by parasitoids. Basic Appl Ecol 13:85-93

Gurr G (2000) Biological control: measures of success. Kluwer Academic Publishers, Dordrecht, p 429

Gurr GM, Wratten SD, Luna JM (2003) Multi-function agricultural biodiversity: pest management and other benefits. Basic Appl Ecol 4:107-116

Haaland C, Naisbit RE, Bersier L-F (2011) Sown wildflower strips for insect conservation: a review. Ins Cons Divers 4:60-80

Hänggi A (1989) Erfolgskontrollen in naturschutzgebieten—gedanken zur notwendigkeit der erfolgskontrolle und vorschlag einer methode der erfolgskontrolle anhand der spinnenfauna. Natur Landschaft 64:143-146

Hänggi A, Stäubli A (2012) Nachträge zum „Katalog der schweizerischen Spinnen“4. Neunachweise von 2002 bis 2011. Arachnologische Mitteilungen 44: 59-76

Hatteland BA, Symondson WOC, King RA, Skage M, Schander C, Solhoy T (2011) Molecular analysis of predation by carabid beetles (Carabidae) on the invasive Iberian slug Arion lusitanicus. Bull Entomol Res 101:675-686

Holland JM (2002) The agroecology of carabid beetles. Intercept Ltd., Bedfordshire, p 356

Holland JM, Reynolds CJM (2003) The impact of soil cultivation on arthropod (Coleoptera and Araneae) emergence on arable land. Pedobiologia 47:181-191 
Huber C, Marggi W (2005) Raumbedeutsamkeit und Schutzverantwortung am Beispiel der Laufkäfer der Schweiz (Coleoptera, Carabidae) mit Ergänzungen zur Roten Liste. Mitteilungen der Schweizer entomologischen Gesellschaft 78:375-397

Jordi B (2010) Bodennutzung im Wandel: Arealstatistik Schweiz. Bundesamt für Statistik, Neuchâtel, p 31

Kotze DJ, O’Hara RB (2003) Species decline-but why? Explanations of carabid beetle (Coleoptera, Carabidae) declines in Europe. Oecologia 135:138-148

Kromp B, Steinberger K-H (1992) Grassy field margins and arthropod diversity: a case study on ground beetles and spiders in eastern Austria (Coleoptera: Carabidae; Arachnida: Aranei, Opiliones). Agric Ecosyst Environ 40:71-93

Landis DA, Wratten SD, Gurr GM (2000) Habitat management to conserve natural enemies of arthropod pests in agriculture. Ann Rev Entomol 45:175-201

Lavandero B, Wratten S, Shishehbor P, Worner S (2005) Enhancing the effectiveness of the parasitoid Diadegma semiclausum (Helen): movement after use of nectar in the field. Biol Control 34:152-158

Limpert E, Stahel WA, Abbt M (2001) Log-normal distributions across the sciences: keys and clues. Bioscience 51:341-352

Löbl I, Smetana A (2003) Archostemata, Myxophage, Adephaga, Catalogue of Palaearctic Coleoptera. Apollo Books, Stenstrup

Luff ML (1987) Biology of polyphagous ground beetles in agriculture. Agric Zoolog Rev 2:237-278

Luka H (1996) Laufkäfer: nützlinge und Bioindikatoren in der Landwirtschaft. Agrarforschung 3:33-36

Luka H (2004) Ökologische Bewertung von Landschaftselementen mit Arthropoden. Opuscula Biogeographica Basileensia 4:1-253

Luka H, Lutz M, Blick T, Pfiffner L (2001) Einfluss von eingesäten Wildblumenstreifen auf die epigäischen Laufkäfer und Spinnen (Carabidae und Araneae) in der intensiv genutzten Agrarlandschaft "Grosses Moos". Schweiz Peckiana 1:45-60

Luka H, Marggi W, Huber C, Gonseth Y, Nagel P (2009) Coleoptera, Carabidae: ecology, atlas. Centre suisse de cartographie de la faune, Neuchâtel, p 677

Marggi WA (1992) Faunistik der Sandlaufkäfer und Laufkäfer der Schweiz (Cicindelidae \& Carabidae, Coleoptera): unter besonderer Berücksichtigung der "Roten Listen" Teil 1: Documenta faunistica helvetiae. Centre suisse de cartographie de la faune, Neuchâtel, p 477

MEA (2005) Ecosystems and human well-being: Synthesis. Island Press, Washington, p 137

Meek B, Loxton D, Sparks T, Pywell R, Pickett H, Nowakowski M (2002) The effect of arable field margin composition on invertebrate biodiversity. Biol Cons 106:259-271

Merckx T, Marini L, Feber RE, Macdonald DW (2013) Hedgerow trees and extended-width field margins enhance macro-moth diversity: implications for management. J Appl Ecol. doi:10.1111/j.13652664.2012.02211.x

Müller-Motzfeld G (2006) Carabidae (Laufkäfer), Band 2, Adephaga 1. In: Freude H, Harde KW, Lohse GA, Klausnitzer B (eds) Die Käfer Mitteleuropas. Spektrum Akademischer Verlag, Heidelberg, pp $1-52$

Nagel P (1999) Biogeographische Raumanalyse und Raumbewertung mit Tieren. In: Schneider-Sliwa R, Schaub D, Gerold G (eds) Angewandte Landschaftsökologie-Grundlagen und Methoden. Springer, Berlin, pp 397-425

Nährig D, Kiechle J, Harms KH (2003) Rote Liste der Webspinnen (Araneae) Baden-Württembergs. Naturschutz-Praxis Artenschutz 7:7-162

Pfiffner L, Luka H (2000) Overwintering of arthropods in soils of arable fields and adjacent semi-natural habitats. Agric Ecosyst Environ 78:215-222

Pfiffner L, Luka H, Schlatter C, Juen A, Traugott M (2009) Impact of wildflower strips on biological control of cabbage lepidopterans. Agric Ecosyst Environ 129:310-314

Pisani Gareau T, Shennan C (2010) Can hedgerows attract beneficial insects and improve pest control? A study of hedgerows on central coast farms. CASFS Cent Res Brief 13:1-9

Platnick NI (2012) The world spider catalog, version 13.0. The American Museum of Natural History. http://research.amnh.org/iz/spiders/catalog/. Accessed Nov 2012

Purvis G, Curry JP (1984) The influence of weeds and farmyard manure on the activity of Carabidae and other ground-dwelling arthropods in a sugar beet crop. J Appl Ecol 21:271-283

R Development Core Team (2009) R: A language and environment for statistical computing. Austria, Vienna

Rainio J, Niemela J (2003) Ground beetles (Coleoptera: Carabidae) as bioindicators. Biodiv Cons 12:487-506

Robinson RA, Sutherland WJ (2002) Post-war changes in arable farming and biodiversity in Great Britain. J Appl Ecol 39:157-176 
Ryan J, Ryan MF, McNaeidhe F (1980) The effect of interrow plant cover on populations of the cabbage root fly, Delia brassicae (Wiedemann). J Appl Ecol 17:31-40

Schellhorn NA, Sork VL (1997) The impact of weed diversity on insect population dynamics and crop yield in collards, Brassica oleraceae (Brassicaceae). Oecologia 111:233-240

Shelton AM, Andaloro JT, Hoy CW (1983) Survey of ground-dwelling predaceous and parasitic arthropods in cabbage fields in upstate New York. Environ Entomol 12:1026-1030

Smith J, Potts SG, Woodcock BA, Eggleton P (2008) Can arable field margins be managed to enhance their biodiversity, conservation and functional value for soil macrofauna? J Appl Ecol 45:269-278

Stoate C, Boatman ND, Borralho RJ, Rio Carvalho C, de Snoo GR, Eden P (2001) Ecological impacts of arable intensification in Europe. J Environ Manag 63:337-365

Suenaga H, Hamamura T (1998) Laboratory evaluation of carabid beetles (Coleoptera: Carabidae) as predators of diamondback moth (Lepidoptera: Plutellidae) larvae. Environ Entomol 27:767-772

Suenaga H, Hamamura T (2001) Occurrence of carabid beetles (Coleoptera: Carabidae) in cabbage fields and their possible impact on lepidopteran pests. Appl Entomol Zool 36:151-160

ter Braak CJF (1996) Unimodal methods to relate species to environment. Centre for Biometry Wageningen (DLO Agricultural Mathematics Group), Wageningen, p 266

ter Braak CJF, Smilauer P (1998) CANOCO reference manual and user's guide to CANOCO for Windows: Software for canonical community ordination (version 4). Microcomputer Power, New York, p 352

Thiele H-U (1977) Carabid beetles in their environments: a study on habitat selection by adaptations in physiology and behaviour. Springer, Berlin, p 369

Tscharntke T, Klein AM, Kruess A, Steffan-Dewenter I, Thies C (2005) Landscape perspectives on agricultural intensification and biodiversity-ecosystem service management. Ecol Lett 8:857-874

Tylianakis JM, Didham RK, Wratten SD (2004) Fitness of aphid parasitoids receiving resource subsidies. Ecology 85:658-666

Weibull A-C, Bengtsson J, Nohlgren E (2000) Diversity of butterflies in the agricultural landscape: the role of farming system and landscape heterogeneity. Ecography 23:743-750 